\title{
PATTERNS OF GASTROPOD ENDEMICITY IN THE GULF OF CALIFORNIA, MEXICO.
}

SIMISON*, Brian W.; LINDBERG, David R., Dept. of Integrative Biology \& Museum of Paleontology, University of California, Berkeley, CA 94720, U.S.A The formation of the Gulf of California completed approximately 10 Mya has overt similarities to the division of the tropical eastern Pacific by the Panamic closure less than 4 Mya. Both geological events involved shallowing of marine habitats, islands separated by basins, and subsequent isolation of their respective faunas. In the Panamic region it was the division into eastern Pacific and Caribbean while in the Gulf it was the separation of the upper Gulf from the temperate Pacific. While the biotic changes associated with the closure of the Panamic portal have been well studied, the formation of the Gulf and its effect on its ancestral biota has not. We examined endemicity patterns in over 1800 species of gastropod molluscs. These patterns were grouped using depth and compared to ranges of taxa that occurred both within and outside of the Gulf. Overall, endemicity patterns within the Gulf are similar to patterns seen in the tropical eastern Pacific. However within the gulf there are marked differences in these patterns between the east and west coasts of the gulf. On the east coast endemic taxa that range from $0-100 \mathrm{~m}$ are more than twice as abundant as endemic taxa on the west coast. In contrast, intertidal endemics on the west coast are almost three times more abundant than on the east coast. We discuss possible scenarios for this difference. 